\title{
Developing and piloting a self-assessment tool for medication review competence of practicing pharmacists based on nationally set competence criteria
}

Noora Lias", Tanja Lindholm, Marika Pohjanoksa-Mäntylä, Aleksi Westerholm and Marja Airaksinen

\begin{abstract}
Background: New competence requirements have emerged for pharmacists as a result of changing societal needs towards more patient-centred practices. Today, medication review competence can be considered as basic pharmaceutical competence. Medication review specific competence criteria and tools for self-assessing the competence are essential in building competences and a shared understanding of medication reviews as a collaborative practice. The aim of this study was to develop and pilot a self-assessment tool for medication review competence among practicing pharmacists in Finland.
\end{abstract}

Methods: The development of the self-assessment tool was based on the national medication review competence criteria for pharmacists established in Finland in 2017 and piloting the tool among practicing pharmacists in a national online survey in October 2018. The pharmacists self-assessed their medication review competence with a five-point Likert scale ranging from 1 for "very poor/not at all" to 5 for "very good".

Results: The internal consistency of the self-assessment tool was high as the range of the competence areas' Cronbach's alpha was 0.953-0.973. The competence areas consisted of prescription review competence (20 items, Cronbach's alpha 0.953), additional statements for medication review competence (11 additional items, Cronbach's alpha 0.963 ) and medication review as a whole, including both the statements of prescription review and medication review competence (31 items, Cronbach's alpha 0.973). Competence items closely related to routine dispensing were most commonly self-estimated to be mastered by the practicing pharmacists who responded $(n=344)$, while the more clinical and patient-centred competence items had the lowest self-estimates. This indicates that the self-assessment tool works logically and differentiates pharmacists according to competence. The self-assessed medication review competence was at a very good or good level among more than half (55\%) of the respondents $(n=344)$.

Conclusion: A self-assessment tool for medication review competence was developed and validated. The piloted self-assessment tool can be used for regular evaluation of practicing pharmacists' medication review competence which is becoming an increasingly important basis for their contribution to patient care and society.

Keywords: Medication review, Professional competence, Self-assessment tool, Professional development, Continuing education, Community pharmacy, Patient centeredness, Medicines policy

*Correspondence: noora.lias@helsinki.fi

Clinical Pharmacy Group, Division of Pharmacology

and Pharmacotherapy, Faculty of Pharmacy, University of Helsinki,

Viikinkaari 5 E, P.O. box 56, 00014 Helsinki, Finland

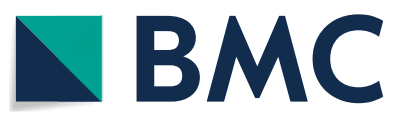

(c) The Author(s) 2021. Open Access This article is licensed under a Creative Commons Attribution 4.0 International License, which permits use, sharing, adaptation, distribution and reproduction in any medium or format, as long as you give appropriate credit to the original author(s) and the source, provide a link to the Creative Commons licence, and indicate if changes were made. The images or other third party material in this article are included in the article's Creative Commons licence, unless indicated otherwise in a credit line to the material. If material is not included in the article's Creative Commons licence and your intended use is not permitted by statutory regulation or exceeds the permitted use, you will need to obtain permission directly from the copyright holder. To view a copy of this licence, visit http://creativecommons.org/licenses/by/4.0/. The Creative Commons Public Domain Dedication waiver (http://creativeco mmons.org/publicdomain/zero/1.0/) applies to the data made available in this article, unless otherwise stated in a credit line to the data. 


\section{Introduction}

Pharmacists are among the professions that face the challenge of developing their competences to meet the changing needs of society. For pharmacists, this means shifting in a more clinical and patient-centred direction to improve the effectiveness of pharmacotherapies and reduce preventable drug-related morbidity and mortality rates $[1-3]$. This trend is reinforced by aging populations worldwide that set new competence requirements for pharmacists. As a result, there has been a global call for community pharmacists to take more responsibility for patient care by reviewing medications for individual patients $[1,4-6]$. This enables identifying, solving and even preventing therapeutically significant medicationrelated problems and risks that are found to be common, especially in older adults [7-17].

Medication review competence can be considered as a contemporary, basic pharmaceutical competence that should be acquired in undergraduate training $[18,19]$. Even so, there are a high number of practicing pharmacists who lack these crucial competences, or at least need to improve their current skills $[4,20]$. Several national and international general level competence frameworks have been developed for pharmacists [21-30]. However, no specific medication review competence criteria nor tools for self-assessing medication review competence have been published so far, although these may be important facilitators for learning. Harmonised concepts and defined contents also can enable building a shared understanding of medication reviews as a collaborative practice. The aim of this study was to develop and pilot a self-assessment tool for medication review competence based on nationally set competence criteria.

\section{Methods}

\section{Context}

This study was conducted in Finland, where community pharmacies are the sole source of prescription and non-prescription medicines in outpatient care [31, 32]. Since 1983, community pharmacists have been obliged to ensure the safe and appropriate use of medicines by counselling while dispensing. Consequently, medication counselling has become an essential task, which is continuously supported by medicine policy initiatives and national development strategies targeting community pharmacy functions [33, 34]. Nowadays community pharmacies are considered one of the most important medicines information sources [35, 36]. However, compared to the shift in tasks, the development of community pharmacists' competence has been lagging behind, even though undergraduate and continuing education have evolved remarkably $[4,20]$.
While communication on medication was enhanced in pharmacies, it became evident that not all medicationrelated problems can be solved by counselling [37-40]. Therefore, a collaborative, comprehensive medication review procedure was developed, and related accreditation training was initiated in Finland in 2005 [41, 42]. The need for specific medication review competence criteria became evident in 2014 when medication review competence was integrated into the pharmacy undergraduate curriculum first at the University of Helsinki as part of the curriculum reform and later in other pharmacy schools $[18,19]$. As no previous competence criteria were found even internationally, The National Coordination Group AATE consisting of key stakeholders in the community pharmacy field started the development process and published the criteria for pharmacist-conducted prescription reviews, medication reviews and comprehensive medication reviews in 2017 [43].

\section{Development of medication review competence criteria}

The development process began by describing the basic features of pharmacist-conducted prescription reviews, medication reviews and comprehensive medication reviews by using the categorisation by the National Health Service (NHS) in the UK [44]. Their categorisation was modified to fit the Finnish context and legislation while taking into account the Finnish Medicines Agency's guidelines on optimising pharmacotherapy for older adults [45], the Medicines Policy 2020 by the Ministry of Social Affairs and Health [33], existing national medication review definitions [46] national and international research on collaborative medication review practices [13, 16, 41, 47-53] and current clinical pharmacy and medication review related undergraduate and continuing education [19].

The competence criteria were developed using a consensus method [43]. The work was led by a working group of medication review experts under the national AATE Coordination Group (later AATE). The working group was responsible for the development rounds and the revision of the draft competence criteria according to the feedback received between the rounds. Five rounds were needed to achieve consensus. Members of the working group and other invited medication review experts acted as an expert panel. Feedback on the draft competence criteria was also received between the rounds from 1) other members of AATE (three rounds of comments), 2) from comprehensive medication review accredited pharmacists $(n=30)$ and 3$)$ from three physicians. Final approval was received from AATE. The final competence criteria included 17 items for prescription review, 10 additional items for medication review and three additional items for comprehensive medication review. 


\section{Development of the self-assessment tool}

The self-assessment tool used in the study was based on the prescription review and medication review competence criteria established by AATE in 2017 (Fig. 1) [43]. At first, the self-assessment tool was piloted among third year pharmacy students at the University of Helsinki in 2017-2018 [54, 55]. This student version was used in the development of the next version of the self-assessment tool. The next version was piloted with a convenience sample of 10 practicing pharmacists during the summer 2018. Based on their feedback, one prescription review related statement was divided into three individual statements and one statement into two. Three of the newlyformed statements were not included in the original AATE competence criteria. These statements were considered necessary regarding medication review competence and were added to the survey by the judgement of the research group. The decision was supported by the working group operating under AATE [43]. Thus, the tool included a total of 31 competence criteria, of which 20 were for the prescription review competence, and the additional 11 were for acquiring medication review competence. The pharmacists were instructed to self-assess their competence with a 5-point Likert scale ranging from 1 for "very poor/not at all" to 5 for "very good". The statements were arranged in an ascending order based on the required competence level (Fig. 2). The competence criteria for prescription reviews came first and then the additional competence criteria for medication reviews.

\section{Data collection}

The data was collected by using an electronic survey targeted to all graduated practicing pharmacists belonging to The Finnish Pharmacists' Association or The Finnish Pharmacists' Society. Pharmacy students were excluded from the survey. There are approximately 9000 pharmacists in Finland, the majority being covered by these two national professional associations. The cover letter for the survey and the link to submit responses electronically were sent through The Finnish Pharmacists' Association to pharmacists who were on their membership registers in October 2018. The Finnish Pharmacists' Society informed its members about the survey via the society's intranet. Two reminders were sent via the associations and the deadline for responses was extended in order to receive more responses.

\section{Data analysis}

The internal consistency of the self-assessment tool was defined using a reliability analysis (Cronbach's alpha).

Data from the pilot self-assessment survey was analysed for descriptive statistics using Microsoft Excel (version 2016) and was presented as frequencies, percentages and summative scales. Two figures were compiled from

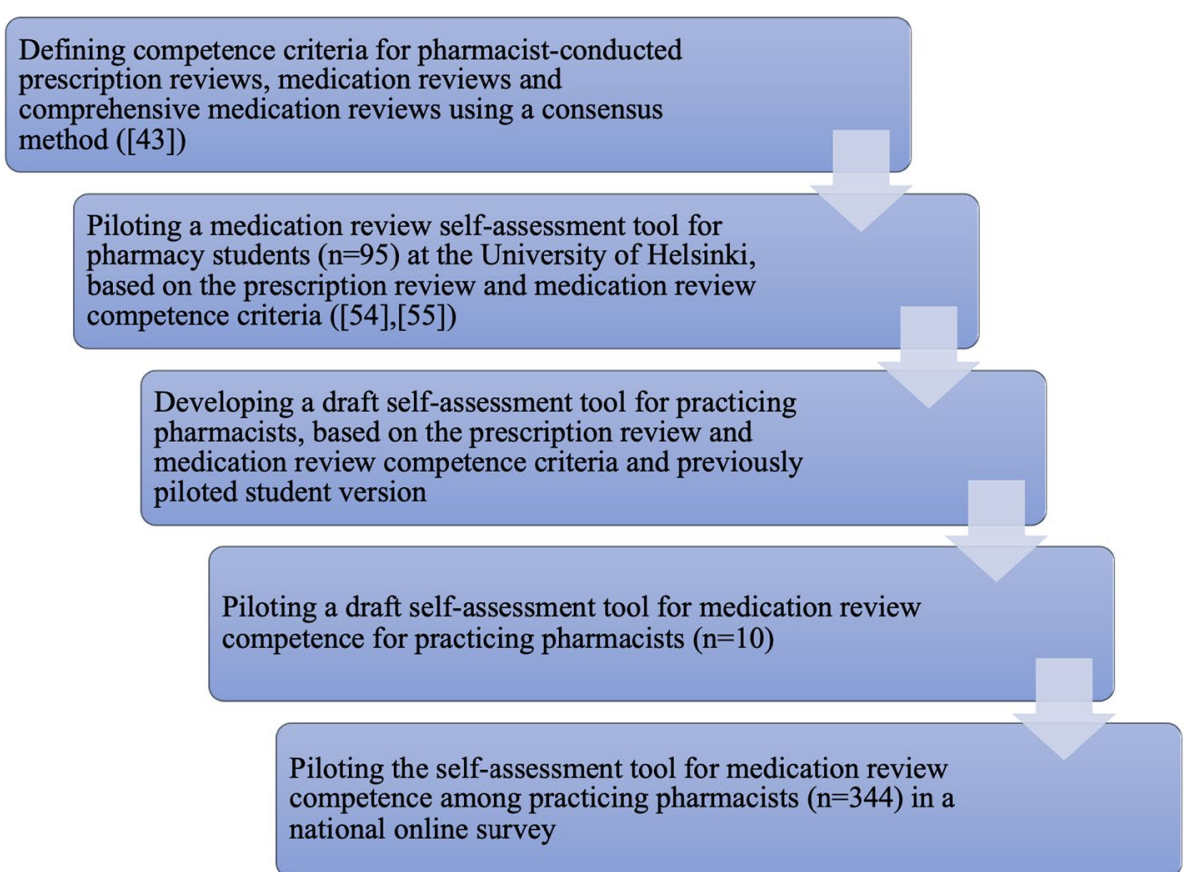

Fig. 1 The development and validation process of the self-assessment tool for medication review competence for practicing pharmacists based on nationally set competence criteria 


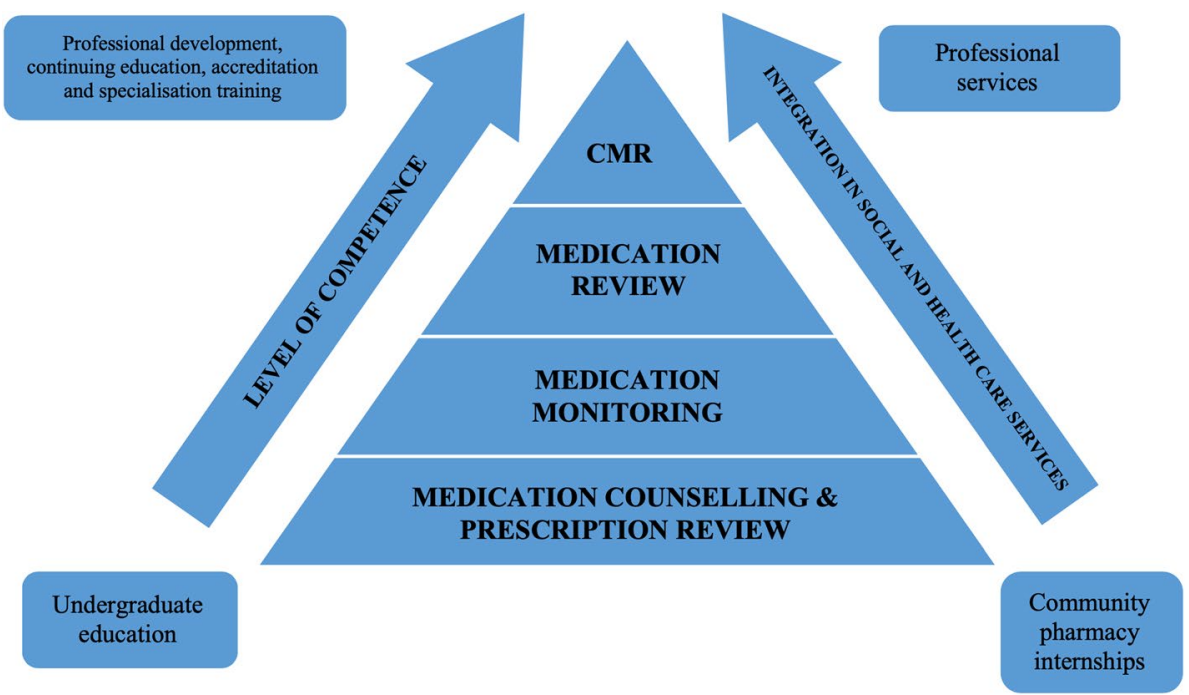

Fig. 2 Illustration of competence development from competence needed in medication counselling towards competence needed in monitoring and reviewing medications $[43,55]$. $C M R=$ Comprehensive medication review requiring accreditation training

Likert scale statements describing self-assessed competence in prescription review (20 statements) and medication review (11 additional statements). Two sum variables were also formed: 1 ) for the self-assessed competence in prescription review (20 statements) and 2) for the selfassessed competence in medication review as a whole including both the competence criteria for prescription review and the additional competence criteria for medication review $(20+11$ statements).

The highest combined "good" and "very good" selfestimates were determined to represent the best competence, whereas the highest combined "very poor/not at all" and "poor" responses were determined to represent the poorest competence. The summative variable for prescription review and medication review competence was formed by giving the respondent a competence score ranging from 1 to 5 , depending on the self-assessment score level, for each of the individual competence criteria (Table 1). Thus, the competence score ranged from 20 to 100 for the 20 prescription review statements and from 31 to 155 for the 31 medication review statements. Grade 1 represented the poorest competence and the grade 5 the highest competence.

\section{Results}

The internal consistency was high for the statements measuring prescription review competence (20 statements, Cronbach's alpha 0.953), medication review competence (11 additional statements, Cronbach's alpha $0.963)$ and medication review competence as a whole (31 statements Cronbach's alpha 0.973) (Table 2).
Table.1 Score limits when forming the summative variables for prescription review $(n=20)$ and medication review $(n=31)$ competences. The score limits were formed by dividing the score range by five. Competence scores were categorised using 5 grades so that grade 1 represented very poor competence, grade 2 poor competence, grade 3 moderate competence, grade 4 good competence and grade 5 very good competence

\begin{tabular}{lll}
\hline Grade & Prescription review & Medication review \\
\hline 1 & $20-35$ & $31-55$ \\
2 & $36-51$ & $56-80$ \\
3 & $52-68$ & $81-105$ \\
4 & $69-84$ & $106-130$ \\
5 & $85-100$ & $131-155$ \\
\hline
\end{tabular}

Table 2 The internal consistency of the competence statements for prescription review and medication review (Cronbach's alpha)

\begin{tabular}{lll}
\hline Level of review & $\begin{array}{l}\text { Number of items } \\
(\mathbf{n})\end{array}$ & Cronbach's alpha \\
\hline Prescription review & 20 & 0.953 \\
$\begin{array}{l}\text { Medication review (addi- } \\
\text { tional statements) }\end{array}$ & 11 & 0.963 \\
$\begin{array}{l}\text { Medication review (as a } \\
\text { whole, a sum variable) }\end{array}$ & 31 & 0.973 \\
\hline
\end{tabular}

By the end of October 2018, a total of 344 practicing pharmacists had responded after extending the deadline for responses and sending two reminders. Most of the respondents (94\%) were female, had a BSc (Pharm) degree $(73 \%)$, worked in a community pharmacy $(64 \%)$ 
and had at least 10 years of work experience (65\%) (Table 3).

\section{Prescription review competence}

The internal consistency of the statements measuring prescription review competence $(n=20)$ was high (Cronbach's alpha 0.953) (Table 2). The highest combined

Table 3 Characteristics of the respondents $(n=344)$

\begin{tabular}{|c|c|c|}
\hline Variable & $\%$ & $n$ \\
\hline \multicolumn{3}{|l|}{ Gender } \\
\hline Female & 94 & 325 \\
\hline Male & 6 & 19 \\
\hline \multicolumn{3}{|l|}{ Degree $^{a}$} \\
\hline BSc (Pharm) & 73 & 253 \\
\hline MSc (Pharm) & 24 & 82 \\
\hline $\mathrm{PhD}$ (Pharm) & 3 & 9 \\
\hline \multicolumn{3}{|l|}{ Previous degree (not pharmacy related) } \\
\hline No previous degree & 66 & 228 \\
\hline \multicolumn{3}{|c|}{$\begin{array}{l}\text { BSc, MSc or PhD at a university or a university of applied } \\
\text { sciences/vocational education and training }\end{array}$} \\
\hline Health care & 13 & 46 \\
\hline Non-health care & 13 & 44 \\
\hline Other & 8 & 26 \\
\hline \multicolumn{3}{|l|}{ Current workplace } \\
\hline Community pharmacy & 64 & 221 \\
\hline Primary or secondary care unit & 21 & 73 \\
\hline Other & 12 & 40 \\
\hline Staff leasing company & 3 & 10 \\
\hline \multicolumn{3}{|l|}{ Work experience as a pharmacist, years } \\
\hline $0-3$ & 13 & 46 \\
\hline $4-9$ & 22 & 76 \\
\hline $10-15$ & 22 & 74 \\
\hline$>15$ & 43 & 148 \\
\hline \multicolumn{3}{|c|}{ Completed long-term continuing or accreditation trainings ${ }^{b}$} \\
\hline Prescription review ${ }^{c}$ & 26 & 89 \\
\hline Medication review ${ }^{d}$ & 16 & 55 \\
\hline Comprehensive medication review ${ }^{e}$ & 13 & 44 \\
\hline Specialisation in ward pharmacy ${ }^{f}$ & 3 & 9 \\
\hline Specialisation in community pharmacy ${ }^{g}$ & 5 & 16 \\
\hline
\end{tabular}

a The university education program in Finland for pharmacists consists of two tiers: the BSc (3 years, 180 ECTS credits) and MSc (5 years, 180 + 120 ECTS credits) curriculums, ECTS: European Credit Transfer System

${ }^{\mathrm{b}}$ The respondents were able to choose several alternatives

'Continuing training offered by the Pharmacy Learning Centre

d 1-year continuing training (20 ECTS credits) or undergraduate studies starting from 2014 at the University of Helsinki, followed by other pharmacy schools in 2017

e 1.5 Years' accreditation training (35 ECTS credits)

${ }^{\mathrm{f}}$ Accreditation training (30 ECTS credits)

${ }^{9}$ Post-graduate programme: BSC (Pharm) 3-year specialisation studies (40 ECTS), MSc (Pharm) 4-year specialisation studies (60 ECTS) "good" and "very good" self-estimates for the 20 competence areas required for conducting prescription reviews were obtained for the following three statements: 1) Understands the importance of medication reconciliation and prescription review in improving medication safety and outcomes $(96 \%), 2)$ Knows how to assure that the dosage, dosage regimen and medicine taking schedule are in line with recommendations (85\%), and 3) Knows basic principles of prescribing, dispensing and reimbursing medicines (85\%) (Fig. 3).

Respectively, the highest combined "very poor/not at all" and "poor" scores were obtained for the following three statements: 1) Can apply pharmacologic, pharmacodynamic, pharmacokinetic and physiologic knowledge to patient care (e.g., considering aging, multiple diseases and medications) (25\%), 2) Knows how to make suggestions for changes to those medication-related problems that were identified in the prescription review (23\%), and 3) Knows clinical pharmacotherapy and guidelines and how to apply the knowledge to patient care to the extent necessary in prescription reviews (21\%) (Fig. 3).

\section{Medication review competence}

The internal consistency of the 11 additional statements measuring medication review competence was high (Cronbach's alpha 0.963) (Table 2). The highest combined "good" and "very good" self-estimates for the 11 competence areas required for conducting medication reviews were obtained in the following three statements: 1) Knows how to review the appropriateness of the entire medication of the patient (40\%), 2) Can apply and customize therapeutic guidelines of the most common diseases, also taking into consideration needs of special populations (38\%), and 3) Knows how to create contacts to social and health care units (38\%) (Fig. 4).

The highest combined" very poor/not at all" and "poor" shares for the competence areas required for conducting medication reviews were obtained for the following three statements: 1) Can apply clinical information from key laboratory tests to patient care and knows which laboratory tests are most important to monitor in each condition and medication (44\%), 2) Knows the principles of clinical interviews and can apply them in practice (42\%), and 3) Can evaluate the clinical significance of observations, form proposals for medication changes and their implementation, and also contribute to their actual implementation (40\%) (Fig. 4).

\section{The summative competence scores in conducting prescription reviews and medication reviews}

Among the respondents, $66 \%$ reached the grade "very good" (21\%) or "good" (45\%) when counting the summative self-assessed competence scores in conducting 


\section{Prescription review competence}

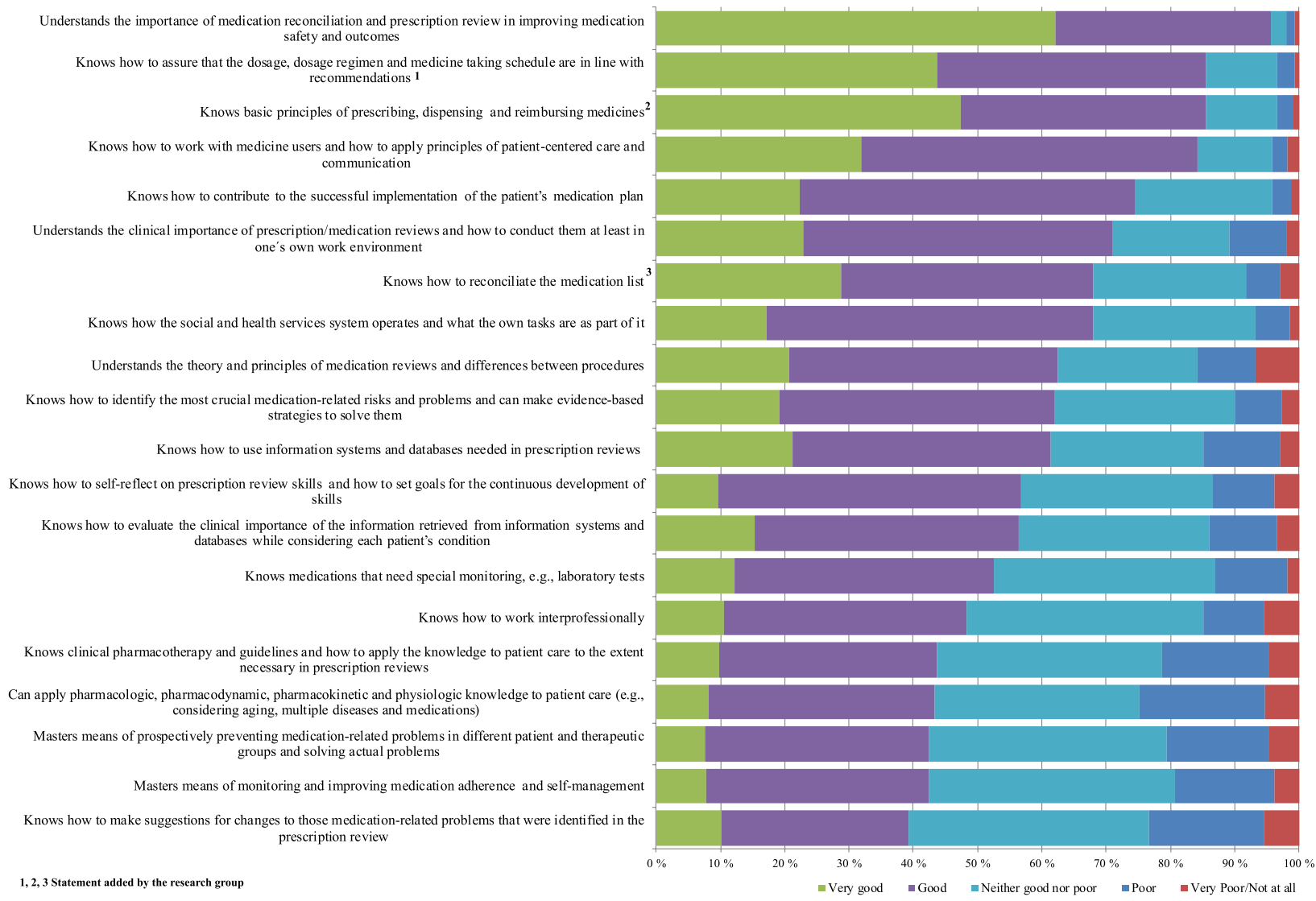

Fig. 3 Self-assessed prescription review competence for practicing pharmacists (\% of the respondents, $n=344$ ). The internal consistency of the statements $(n=20)$ in the reliability analysis was 0.953 (Cronbach's alpha)

prescription reviews. For $6 \%$ of respondents, their selfassessed prescription review competence was graded as "very poor/not at all" or "poor" based on the summative competence scores (Fig. 5). Among the respondents, 55\% reached the grade "very good" (13\%) or "good" (42\%) when the summative self-assessed competence scores in conducting medications reviews were counted. Twelve percent of the respondents' self-assessed medication review competence was graded as "very poor/not at all" or "poor" based on the summative competence scores (Fig. 5).

\section{Future prospects of medication review education}

The majority of the respondents $(80 \%)$, who did not possess medication review expertise at the time of the study, were willing to complete or verify this in the future. Online-education (39\%) and long-term continuing education $(30 \%)$ were the preferred methods. Six percent had chosen the "Other, please specify" -alternative and suggested, for example, a multi-modal course, combining online and on-the-job training.

\section{Discussion}

The self-assessment tool for medication review competence can be considered valid and able to distinguish different levels of competence as the Cronbach's alpha value is $>0.70$ at all points $([56,57]$, Table 2$)$. The results for prescription review and medication review were logical, i.e., self-assessed prescription review expertise was at a higher level than medication review expertise that requires a higher level of competence.

To our knowledge, this was the first attempt to develop a tool measuring medication review competence of pharmacists as no previous tool or medication review specific competence criteria were found in an extensive international inventory during the development process of the national competence criteria [43]. The competence criteria for prescription and medication review that functioned as the self-assessment tool's basis were thoroughly and rigorously developed by national experts in the area during a multistage process. Since then, the tool has been piloted by both pharmacy students and practicing pharmacists and modified based on the feedback 


\section{Medication review competence}

Knows how to review the appropriateness of the entire medication of the patient

Can apply and customize therapeutic guidelines of the most common diseases, also taking into consideration needs of special populations

Knows how to create contacts to social and health care units

Can target medication reviews to patients having such severe medication-related problems that they cannot be solved by prescription reviews

Can prioritize and reason proposals for clinically important medication changes

Masters key principles of implementing medication changes, such as deprescribing and monitoring of deprescribing outcomes

Can work as an expert in an interprofessional team and make valid observations about the patient's medication

Can make recommendations for monitoring medication changes and contribute to the monitoring

Can evaluate the clinical significance of observations, form proposals for medication changes and their implementation, and also contribute to their actual implementation

Knows the principles of clinical interviews and can apply them in practice

Can apply clinical information from the key laboratory tests to patient care and knows which laboratory tests are most important to monitor in each condition and medication

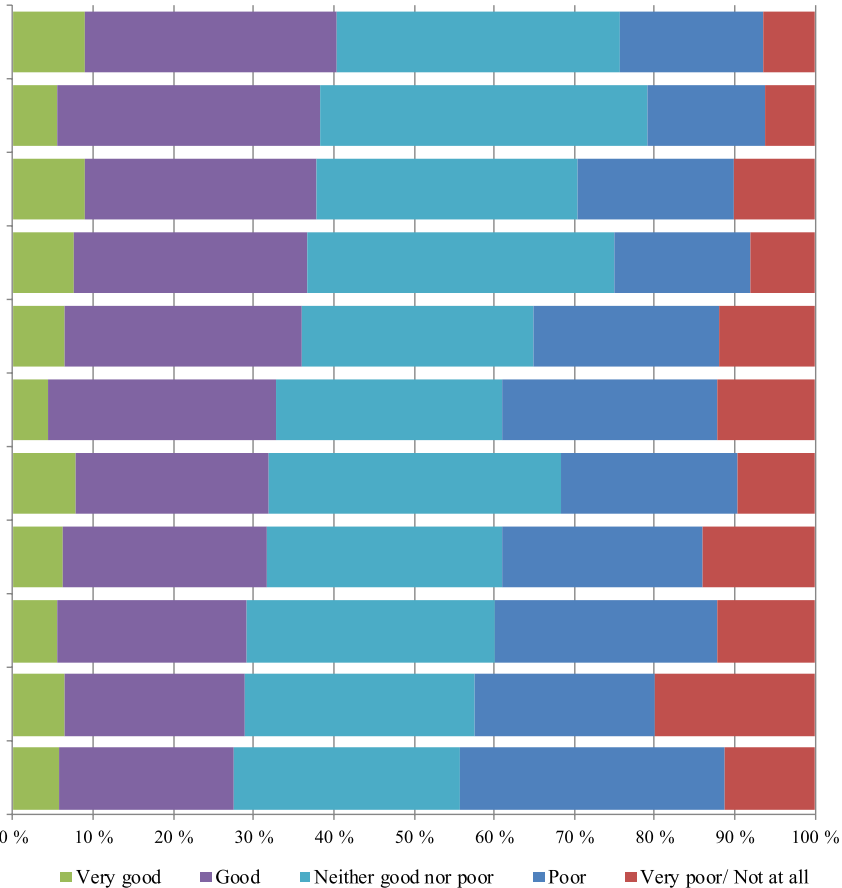

Fig. 4 Self-assessed medication review competence of the practicing pharmacists (\% of the pharmacists, $n=344$ ). The internal consistency of the statements $(n=11)$ in the reliability analysis was 0.963 (Cronbach's alpha)

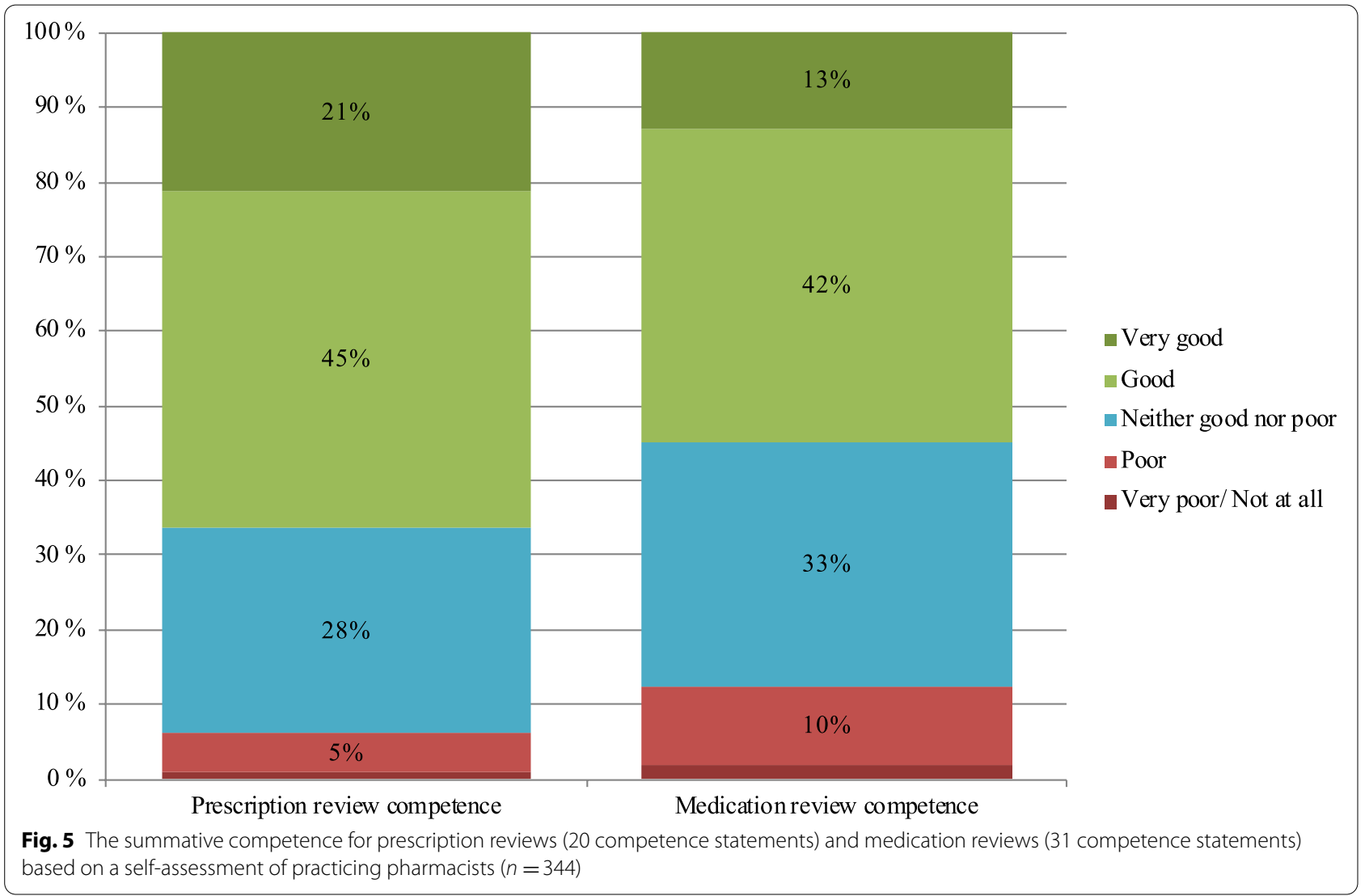


$[43,54,55]$. In the absence of equivalent self-assessment tools to compare with, the researchers applied a scoring system based on a five-point Likert scale, which is frequently used in self-assessment studies, to measure the competence for each item and to compose the sum variables. Thus, the self-assessment tool's scores with grades ranging from 1 to 5 were considered to reflect the competence levels of the pharmacists. Most of the existing competence frameworks for pharmacists are very broad and, therefore, represent massive entities that remain at a general level [21-30]. It would be useful to fine-tune the frameworks and make them more focused and detailed, even split them into several specialty areas, one of them being medication review competences. This would also raise awareness of what the competence requirements of pharmacy professionals are and which competences should be developed [58]. Hopefully, the self-assessment tool that was created in this study will raise discussion and undergo further development that will enable its utilization in national and international pharmacy practice contexts.

Based on the findings of the pilot study, the selfassessed medication review competence was at a very good or good level among more than half (55\%) of the practicing pharmacists who responded (Fig. 5). In general, it can be noticed that the "very good" proportions decreased sharply when moving from the competence criteria for prescription review to the competence criteria for medication review. Correspondingly, the "very poor/ not at all" proportions increased when moving from the competence criteria for prescription review to the competence criteria for medication review. This reflects a more comprehensive management of prescription review related skills compared to medication review related skills. This is in line with the fact that medication review expertise requires separate additional training or completion of the BSc (Pharm) degree by following the renewed undergraduate curriculum (started in 2014) [18].

According to a previous self-assessment study, thirdyear pharmacy students at the University of Helsinki who had attended the reformed BSc (Pharm) curriculum, had a higher level of self-assessed medication review competence than the practicing pharmacists participating in this study $[54,55]$. This may indicate that the integration of medication review competence into the BSc (Pharm) curriculum has achieved the set goals of developing the competences towards a clinical and patientcentred direction. Previous international studies have made similar observations about the better self-assessed competence of the younger generation, but also about the growing need for postgraduate training and the mismatch or outright lack of its provision, with prevailing and rapidly changing competence requirements in the field [58-60]. This, in turn, indicates the existence of intergenerational competence gaps, although it should be noted that our results may be affected by a low response rate and the Dunning-Kruger effect [61, 62]. Thus, more efforts need to be directed towards previously graduated practicing pharmacists to keep their competences updated.

Developing easy-to-use competence self-assessment tools for practicing pharmacists, such as the one developed in this study, could support the desired shift from drug-centred pharmacy practice towards a more patient-centred one by identifying competence gaps and educational needs $[1,63,64]$. The findings from this self-assessment pilot survey indicate that drug-centred competences related to dispensing were still the best mastered ones. The results are in line with previous international studies [65-67]. They may reflect the fact that the real-life pharmacy practice and education in Finland and elsewhere, have mainly focused on these drug-centred practices and competences.

In line with previous studies, shortcomings in applied clinical pharmacotherapy competences were implied [54, $55,63,65,68,69]$. This concerns key competences needed for reviewing medications, such as estimating the clinical significance of the identified medication-related problems and risks, participating in implementing medication changes and interpreting and understanding laboratory test values. As the proportion of the aging population is growing, the importance of geriatric applied pharmacotherapy will also increase because of many age-related factors influencing drug suitability and dosing [20, 51, 70]. Furthermore, addressing the implied competence gaps related to interprofessional collaboration and collaboration with patients and their proxies could support medication adherence and self-management, also avoid preventable harm $[4,15,20,45,52,53,71-74]$.

Additional education could increase pharmacists' clinical competence and promote the implementation of pharmaceutical care and patient-centred practice [7578]. According to this pilot study, practicing pharmacists are interested in developing, complementing and validating their medication review skills, primarily in the form of online education and long-term continuing education. In line with the results of this pilot survey, it can be generally noted that pharmacists want to stay informed about the advances of their profession and are willing to maintain and develop their professional competence to meet the needs of a changing society $[63,64,79,80]$.

\section{Strengths and limitations of the study}

The internal consistency of the result descriptors and sum variables was defined using a reliability analysis (Cronbach's alpha) (Table 2) [56, 57]. Cronbach's alpha 
value was high as it was $>0.70$ at all points. Content and face validity were supported by the facts that the competence criteria were developed by medication review experts in Finland and that the self-assessment tool was piloted among third year pharmacy students $(n=95)$ of the University of Helsinki, as well as among practicing pharmacists ( $n=10 ; 5$ with a BSc (Pharm) degree, 5 with a MSc (Pharm) degree) [43, 54, 55, 81]. Construct validity was supported by a high Cronbach's alpha value and by the fact that the results of the survey were logical, i.e., the "very good" proportions decreased sharply when moving from the competence criteria for prescription review to the competence criteria for medication review. Similarly, the "very poor/not at all" proportions increased when moving from the competence criteria for prescription review to the competence criteria for medication review.

The number of respondents $(n=344)$ in this study was low but adequate for the purposes of a pilot validation study [57]. However, national generalisations of the results cannot be made based on this study. The survey had interested most practicing pharmacists with at least 15 years of work experience as $43 \%$ of the respondents were from this segment. They can be considered the main target group for efforts to maintain professional competence updated. It was not possible to calculate the response rate. This is because The Finnish Pharmacists' Society informed its members about the survey via the Society's intranet, so the exact number of the target population is not known. As the respondents were presumably interested in and familiar with the topic, with more in-depth knowledge the results may give an overly optimistic picture of medication review competences in general. The majority of the respondents worked in community pharmacies $(64 \%)$ or in primary or secondary care $(21 \%)$ in which collaborative medication reviews are supposed to be implemented and conducted $[15,16$, 82-85]. Furthermore, the Dunning-Kruger effect relating to self-assessment, i.e., the bias of superiority where an individual overestimates his or her competence can be considered a limitation of the survey [61, 62].

\section{Practical implications}

The self-assessment tool for medication review competence developed in the study can be used to identify medication review competence gaps and to monitor the development of the national implementation of medication review competence in the future. It can serve as a model when designing similar studies or tools internationally. The self-assessment tool can be used by practicing pharmacists when self-reflecting upon their competence and use the information gained, for example, in professional development discussions or when considering verifying the medication review competence through the portfolio-based verification process. The self-assessment tool for medication review competence has already been used as a basis for a self-assessment tool in the portfolio-based verification process of medication review competence in Finland. The study gave an insight into the competence gaps and educational needs of practicing pharmacists and the direction in which education and competence should be developed in the future.

\section{Further research}

The development of the situation concerning medication review competence should be monitored periodically, for example, by conducting a self-assessment tool-based survey every 5 years. In this way, information on the implementation of the medication review competence in the pharmacy field is provided and the competence to work as part of healthcare is ensured. Further research is needed regarding the implementation of medication review practices, especially in the community pharmacy setting.

\section{Conclusions}

A self-assessment tool for medication review competence was developed and validated. The results were logical, and the tool was found to be able to distinguish different levels of competence and reveal competence gaps. Activities related to dispensing were self-assessed at the best level. Educational needs were identified regarding patient-centred and clinical competence. The results are in line with previous international studies and reflect competence areas which have traditionally been considered a strong area of expertise in the pharmacy field. Continuing and postgraduate medication review training is required for pharmacists who have previously graduated to effectively implement medication review competence within the profession. The self-assessment tool for medication review competence can be used as a regular monitoring tool for evaluating practicing pharmacists' medication review competence and directing continuing education.

\footnotetext{
Acknowledgements

We want to express our gratitude to especially Sanna Passi as well as the other members of the AATE Coordination Group for their input and guidance. We would also like to thank Akseli Pöykkö for his technical assistance.
}

\section{Authors' contributions}

N.L. and T.L. contributed equally to this work. N.L., T.L., M.P-M., A.W. and M.A. contributed to the study concept and design, as well as the interpretation of data. N.L. and T.L. were both responsible for the statistical analyses and drafting of the manuscript. All authors contributed to the preparation of the manuscript and read and approved the final manuscript.

\section{Funding}

This research did not receive any specific grant from funding agencies in the public, commercial, or not-for-profit sectors. Open access publishing funded by Helsinki University Library. 


\section{Availability of data and materials}

The datasets used and/or analysed during the current study are available from the corresponding author on reasonable request.

\section{Declarations}

\section{Ethics approval and consent to participate}

The study was conducted in accordance with the national guidelines for responsible conduct of research and procedures for handling allegations of misconduct in Finland by the Finnish Advisory Board on Research Integrity [86]. The ethical principles of research with human participants and ethical review in the human sciences in Finland by the Finnish National Board on Research Integrity were also followed [87]. According to the guidelines, a review by the research ethics committee and their approval were not required for this study. The Finnish Pharmacists' Association and The Finnish Pharmacists' Society granted research permission before submitting the electronic survey. The respondents' privacy was secured as the researchers never handled the identity information of the respondents and communication about the research and survey was only carried out by the organisations [87]. Respondents were aware that their responses would be treated anonymously and used for research purposes only. Informed consent was obtained from all the participants. Responding to the survey and thereby participating in the study were voluntary.

\section{Consent for publication}

Not applicable.

\section{Competing interests}

The authors declare that they have no competing interests.

Received: 15 June 2021 Accepted: 15 November 2021

Published online: 25 November 2021

\section{References}

1. Hepler CD, Strand LM. Opportunities and responsibilities in pharmaceutical care. Am J Hosp Pharm. 1990;47(3):533-42.

2. International Pharmaceutical Federation. Good Pharmacy Practice. Joint FIP/WHO guidelines on GPP: Standards for quality of pharmacy services. 2011. https://www.fip.org/file/1476. Accessed 14 Jun 2020.

3. World Health Organization. Medication without harm - Global patient safety challenge on medication safety. 2017. http://www.gims-found ation.org/wp-content/uploads/2017/05/WHO-Brochure-GPSC_Medic ation-Without-Harm-2017.pdf. Accessed 14 Jun 2020.

4. Kallio S, Eskola T, Pohjanoksa-Mäntylä M, Airaksinen M. Medication risk management in routine dispensing in community pharmacies. Int J Environ Res Public Health. 2020;17:8186. https://doi.org/10.3390/ijerph1721 8186

5. Mossialos E, Courtin E, Naci H, Benrimoj S, Bouvy M, Farris K, et al. From "retailers" to health care providers: transforming the role of community pharmacists in chronic disease management. Health Policy. 2015:119:628-39. https://doi.org/10.1016/j.healthpol.2015.02.007.

6. Bryant L, Maney J, Martini N. Changing perspectives of the role of community pharmacists: 1998-2012. J Prim Health Care. 2017;9:34-46. https://doi.org/10.1071/HC16032.

7. Vinks T, Koning F, Lange T, Egberts T. Identification of potential drug-related problems in the elderly: the role of the community pharmacist. Pharm World Sci. 2006;28:33-8. https://doi.org/10.1007/ s11096-005-4213-4

8. Bryant LM, Coster G, Gamble GD, McCormick RN. The general practitioner-pharmacist collaboration (GPPC) study: a randomised controlled trial of clinical medication reviews in community pharmacy. Int J Pharm Pract. 2011;19:94-105. https://doi.org/10.1111/j.2042-7174.2010.00079.x.

9. Kaur S, Mitchell G, Vitetta L, Roberts MS. Interventions that can reduce inappropriate prescribing in the elderly: a systematic review. Drugs Aging. 2009;26:1013-28.

10. Krska J, Avery AJ. Evaluation of medication reviews conducted by community pharmacists: a quantitative analysis of documented issues and recommendations. Br J Clin Pharmacol. 2008;65:386-96. https://doi.org/ 10.1111/j.1365-2125.2007.03022.x

11. Patterson SM, Cadogan CA, Kerse N, Cardwell CR, Bradley MC, Ryan C, et al. Interventions to improve the appropriate use of polypharmacy for older people. Cochrane Database Syst Rev. 2014;10. https://doi.org/10. 1002/14651858.CD008165.pub3.

12. Janknegt R. Medication reviews. Eur J Hosp Pharm Sci Pract. 2015. https:// doi.org/10.1136/ejhpharm-2015-000669.

13. Kiiski A, Kallio S, Pohjanoksa-Mäntylä M, Kumpusalo-Vauhkonen A, Järvensivu T, Airaksinen M, et al. Rationalization of pharmacotherapy for the elderly as an inter-professional collaboration. Systematic review. The Ministry of Social Affairs and Health. 2016. http://urn.fi/URN:ISBN:978-95200-3704-8. Accessed 02 Aug 2018. (Only in Finnish).

14. Huiskes VJB, Burger DM, Ende CHM, Bemt BJF. Effectiveness of medication review: a systematic review and meta-analysis of randomized controlled trials. BMC Fam Pract. 2017;18:5. https://doi.org/10.1186/ s12875-016-0577-X

15. Kallio SE, Kiiski A, Airaksinen MSA, Mäntylä AT, Kumpusalo-Vauhkonen A, Järvensivu TP, et al. Community pharmacists' contribution to medication reviews for older adults: a systematic review. J Am Geriatr Soc. 2018;66:1613-20

16. Kiiski A, Airaksinen M, Mäntylä A, Desselle S, Kumpusalo-Vauhkonen A, Järvensivu T, et al. An inventory of collaborative medication reviews for older adults - evolution of practices. BMC Geriatr. 2019;19:1-11. https:// doi.org/10.1186/s12877-019-1317-6.

17. Imfeld-Isenegger T, Soares IB, Makovec UN, Horvat N, Kos M, van Mil F, et al. Community pharmacist-led medication review procedures across Europe: characterization, implementation and remuneration. Res Soc Adm Pharm. 2020;16:1057-66. https://doi.org/10.1016/j.sapharm.2019.11. 002.

18. University of Helsinki. Pharmacy curriculum reform 2014 - Final report of the planning group. Helsinki: Faculty of Pharmacy; 2014.

19. Niittynen I, Pajunen A, Airaksinen M, Pietilä K, Kiiski A. Capacity of teaching community pharmacies to instruct students on medication reviews as part of internship. Dosis. 2017;33:54-66 English summary.

20. Kallio S, Eskola T, Airaksinen M, Pohjanoksa-Mäntylä M. Identifying gaps in community pharmacists' competence in medication risk management in routine dispensing. Innov Pharm. 2021;12:8. https://doi.org/10.24926/iip. v12i1.3510.

21. Thai Pharmacy Council. Standard criteria for pharmacy practitioners. 2002.

22. National Association of Pharmacy Regulatory Authorities (NAPRA). Model Standards of Practice for Canadian Pharmacists. 2003. https://cdn.dal. $\mathrm{ca} /$ content/dam/dalhousie/pdf/faculty/faculty-health-professions/cpe/ CPE\%20PDF/model_standards_of_practice_for_Canadian_Pharmacists. pdf. 2003. Accessed 06 Jun 2020.

23. Competency development and evaluation group. General Level Framework. A framework for pharmacist development in general pharmacy practice. 2007

24. Mills E, Bates I, Farmer D, Davies G, Webb DG. The general level framework: use in primary care and community pharmacy to support professional development. Int J Pharm Pract. 2008;16:325-31. https://doi.org/ 10.1211/ijpp.16.5.0008.

25. Albanese NP, Rouse MJ, Schlaifer M. Scope of contemporary pharmacy practice: roles, responsibilities, and functions of pharmacists and pharmacy technicians. J Am Pharm Assoc. 2010;50:35-69. https://doi.org/10. 1331/JAPhA.2010.10510.

26. International Pharmaceutical Federation. A Global Competency Framework for Services Provided by Pharmacy Workforce. 2012. https://www. fip.org/file/1412. Accessed 12 May 2020

27. Pharmacy Council of New Zealand. Competence Standards for the Pharmacy Profession. 2015. https://www.pharmacycouncil.org.nz/dnn_ uploads/Documents/standardsguidelines/CompStds2015Web.pdf?ver= 2017-02-20-104344-177. Accessed 06 Jun 2020.

28. Atkinson J, De Paepe K, Pozo AS, Rekkas D, Volmer D, Hirvonen J, et al. The second round of the PHAR-QA survey of competences for pharmacy practice. Pharmacy (Basel). 2016. https://doi.org/10.3390/pharmacy40 30027.

29. Pharmaceutical Society of Australia. National Competency Standards for Pharmacists in Australia. 2016. https://www.psa.org.au/wp-content/uploa 
ds/2018/06/National-Competency-Standards-Framework-for-Pharm acists-in-Australia-2016-PDF-2mb.pdf. Accessed 12 May 2020.

30. Saseen JJ, Ripley TL, Bondi D, Burke JM, Cohen LJ, McBane S, et al. ACCP clinical pharmacist competencies. Pharmacotherapy. 2017;37:630-6. https://doi.org/10.1002/phar.1923.

31. Medicines Act 395/1987. The Act came into force on 10 April 1987. https://finlex.fi/en/laki/kaannokset/1987/en19870395. Accessed 15 May 2021.

32. The Finnish Medicines Agency Fimea. Rational use of medicines through information and guidance medicines information services: current state and strategy for 2020. 2012. http://urn.fi/URN:ISBN\%20978-952-562420-5. (Summary in English).

33. The Ministry of Social Affairs and Health. Medicines Policy 2020. Towards efficient, safe, rational and cost-effective use of medicines: Publications of the Ministry of Social Affairs and Health; 2011. http://urn.fi/URN:ISBN: 978-952-00-3165-7

34. The Ministry of Social Affairs and Health. Rational pharmacotherapy action plan. Final report. Reports and memorandums of the Ministry of Social Affairs and Health 19/2018. The Ministry of Social Affairs and Health, Helsinki, Finland 2018. http://urn.fi/URN:ISBN:978-952-00-3930-1.

35. Mononen N, Pohjanoksa-Mäntylä M, Airaksinen MS, Hämeen-Anttila K. How far are we from a medication use process aiming at well-informed adherent patients with long-term medications in Finland? Qualitative study. BMJ Open. 2020;10:e036526. https://doi.org/10.1136/bmjop en-2019-036526.

36. Mononen N. From paper to cyber - medicines information as a strategic goal in Finland and the European Union: Doctoral dissertation. University of Helsinki; 2020. http://urn.fi/URN:ISBN:978-951-51-5883-3

37. Varunki M, Puumalainen I, Kansanaho H, Airaksinen M. Developing professional community pharmacy services in Finland - Implementation of TIPPA project (2000-2003). Dosis. 2004;20:119-29 English summary.

38. Puumalainen I. Development of instruments to measure the quality of patient counselling: Doctoral dissertation. University of Kuopio; 2005. http://urn.fi/URN:ISBN:951-27-0053-0

39. Kansanaho H. Implementation of the principles of patient counselling into practice in Finnish community pharmacies: Doctoral dissertation. University of Helsinki; 2006. http://urn.f/URN:ISBN:952-10-2877-7

40. Airaksinen M, Toivo T, Jokinen L, Savela E, Parkkamäki S, Sandler C, et al. Policy and vision for community pharmacies in Finland: A roadmap towards enhanced integration and reduced costs. Pharm Pract (Granada). 2021;19:2288. https://doi.org/10.18549/PharmPract.2021.1.2288.

41. Leikola S. Development and application of comprehensive medication review procedure: Doctoral dissertation. University of Helsinki; 2012. http://urn.fi/URN:ISBN:978-952-10-7698-5

42. Leikola S, Tuomainen L, Peura S, Laurikainen A, Lyles A, Savela E, et al. Comprehensive medication review: development of a collaborative procedure. Int J Clin Pharm. 2012;34:510-4. https://doi.org/10.1007/ s11096-012-9662-y

43. The National Coordination Group of Professional Development of Pharmacy Services (AATE). Medication review competence recommendations for pharmacists working in community pharmacies and other health care settings. Dosis. 2017;33:199-209 English summary.

44. Clyne W, Blenkinsopp A, Seal R. A guide to medication review 2008. 2008. https://www.cff.org.br/userfiles/52\%20-\%20CLYNE\%20W\%20A\%20gui de\%20to\%20medication\%20review\%202008.pdf. Accessed 22 Jan 2020.

45. Kumpusalo-Vauhkonen A, Järvensivu T, Mäntylä A. A multidisciplinary approach to promoting sensible pharmacotherapy among aged persons - a national assessment and recommendations. 2016. http://urn.fi/URN: ISBN:978-952-5624-65-6. (English summary).

46. Peura S, Ovaskainen H, Lehtonen A, Wiberg I, Airaksinen M, Hakkarainen $\mathrm{K}$, et al. Comprehensive medication review involving collaboration between pharmacists and physicians - experiences of developing the procedure in Finland. Dosis. 2007;23:20-8 English summary.

47. Bulajeva A, Labberton L, Leikola S, Pohjanoksa-Mäntylä M, Geurts MME, de Gier JJ, et al. Medication review practices in European countries. Res Soc Adm Pharm. 2014;10:731-40. https://doi.org/10.1016/j.sapharm.2014. 02.005 .

48. Dimitrow SM. Development and validation of a drug-related problem risk assessment tool for use by practical nurses working with communitydwelling aged: Doctoral dissertation. University of Helsinki; 2016. http:// urn.fi/URN:ISBN:978-951-51-2618-4
49. National Institute for Health and Care Excellence (NICE). Medicines optimisation. Quality standard. 2016. https://www.nice.org.uk/guida nce/qs120/resources/medicines-optimisation-pdf-75545351857861. Accessed 22 Jan 2020.

50. Viswanathan M, Kahwati LC, Golin CE, Blalock SJ, Coker-Schwimmer E, Posey $R$, et al. Medication therapy management interventions in outpatient settings: a systematic review and meta-analysis. JAMA Intern Med. 2015;175:76-87.

51. Toivo T, Dimitrow M, Puustinen J, Savela E, Pelkonen K, Kiuru V, et al. Coordinating resources for prospective medication risk management of older home care clients in primary care: procedure development and RCT study design for demonstrating its effectiveness. BMC Geriatr. 2018;18. https://doi.org/10.1186/s12877-018-0737-z.

52. Kallio S, Kumpusalo-Vauhkonen A, Järvensivu T, Mäntylä A, PohjanoksaMäntylä M, Airaksinen M. Towards interprofessional networking in medication management of the aged: current challenges and potentia solutions in Finland. Scand J Prim Health Care. 2016;34:368-76. https:// doi.org/10.1080/02813432.2016.1249055.

53. Chen T. Pharmacist-led home medicines review and residential medication management review: the Australian model. Drugs Aging. 2016;33:199-204. https://doi.org/10.1007/s40266-016-0357-2.

54. Westerholm A. Medication review competency among third-year pharmacy students at the University of Helsinki: Bachelor's Thesis. University of Helsinki; 2018.

55. Westerholm A, Leiman K, Kiiski A, Pohjanoksa-Mäntylä M, Mistry A, Airaksinen $\mathrm{M}$. Fostering medication review competency in undergraduate pharmacy training: a self-assessment by third-year students. Submitted manuscript, 2021.

56. Tavakol M, Dennick R. Making sense of Cronbach's alpha. Int J Med Educ. 2011;2:53-5. https://doi.org/10.5116/ijme.4dfb.8dfd.

57. Boateng GO, Neilands TB, Frongillo EA, Melgar-Quiñonez HR, Young SL. Best practices for developing and validating scales for health, social, and behavioral research: a primer. Front Public Health. 2018;6:149. https://doi. org/10.3389/fpubh.2018.00149.

58. Mills E, Laaksonen R, Bates I, Davies G, Duggan C. Self-assessment of competence in a community pharmacy setting. Pharm Educ. 2005;5:1-11. https://doi.org/10.1080/15602210500282491.

59. Jungnickel PW, Kelley KW, Hammer DP, Haines ST, Marlowe KF. Addressing competencies for the future in the professional curriculum. Am J Pharm Educ. 2009;73:156. https://doi.org/10.5688/aj7308156.

60. McLaughlin JE, Bush AA, Rodgers PT, Scott MA, Zomorodi M, Pinelli NR, et al. Exploring the requisite skills and competencies of pharmacists needed for success in an evolving health care environment. Am J Pharm Educ. 2017:81:116. https://doi.org/10.5688/ajpe816116.

61. Kruger J, Dunning D. Unskilled and unaware of it: how difficulties in recognizing one's own incompetence lead to inflated self-assessments. J Pers Soc Psychol. 1999;77:1121-34. https://doi.org/10.1037/0022-3514. 77.6.1121.

62. Pennycook G, Ross RM, Koehler DJ, Fugelsang JA. Dunning-Kruger effects in reasoning: theoretical implications of the failure to recognize incompetence. Psychon Bull Rev. 2017;24:1774-84. https://doi.org/10.3758/ S13423-017-1242-7.

63. Schindel TJ, Yuksel N, Breault R, Daniels J, Varnhagen S, Hughes CA. Pharmacists'learning needs in the era of expanding scopes of practice: evolving practices and changing needs. Res Soc Adm Pharm. 2019;15:448-58. https://doi.org/10.1016/j.sapharm.2018.06.013.

64. Bryant $L$, Coster G, McCormick R. Community pharmacist perceptions of clinical medication reviews. J Primary Healthc. 2010;2:234-42. https://doi. org/10.1071/HC10234.

65. Meštrović A, Staničić Z, Hadžiabdić MO, Mucalo I, Bates I, Duggan C, et al. Evaluation of Croatian community pharmacists' patient care competencies using the general level framework. Am J Pharm Educ. 2011;75. https://doi.org/10.5688/ajpe75236.

66. Držaić M, Kummer I, Mucalo I, Bruno A, Ortner HM. Identifying selfassessed competencies and areas for improvement within community pharmacist-preceptors support during pre-registration training. BMC Med Educ. 2018;18. https://doi.org/10.1186/s12909-018-1413-x.

67. Mann JE, Amerine LB, Waldron K, Wolcott MD, McLaughlin JE. Pharmacist perceptions of competency: identifying priority areas for a competency program development at an academic medical center. Res Soc Adm Pharm. 2018;14:595-602. https://doi.org/10.1016/j.sapharm.2017.07.008. 
68. McIntosh T, Munro K, McLay J, Stewart D. A cross sectional survey of the views of newly registered pharmacists in Great Britain on their potential prescribing role: a cautious approach. Br J Clin Pharmacol. 2012;73:65660. https://doi.org/10.1111/j.1365-2125.2011.04133.x

69. Safaeian L, Mostafavi SA, Changiz T, Mirzadeh M. Pharmacists' opinions and self-reporting performance regarding the professional tasks and responsibilities in Isfahan, Iran. J Educ Health Promot. 2014;3. https://doi. org/10.4103/2277-9531.127544.

70. Klotz U. Pharmacokinetics and drug metabolism in the elderly. Drug Metab Rev. 2009;41:61-76. https://doi.org/10.1080/03602530902722679.

71. Clements D, Dault M, Priest A. Effective teamwork in healthcare: research and reality. Healthc Pap. 2007;7:26-34.

72. Xyrichis A, Lowton K. What fosters or prevents interprofessional teamworking in primary and community care? A literature review. Int J Nurs Stud. 2008:45:140-53. https://doi.org/10.1016/j.ijnurstu.2007.01.015.

73. Steinman MA, Hanlon JT. Managing medications in clinically complex elders: "There's got to be a happy medium". JAMA. 2010;304:1592-601. https://doi.org/10.1001/jama.2010.1482.

74. Rose $\mathrm{O}$, Mennemann H, John C, Lautenschläger M, Mertens-Keller D, Richling K, et al. Priority setting and influential factors on acceptance of pharmaceutical recommendations in collaborative medication reviews in an ambulatory care setting - analysis of a cluster randomized controlled trial (WestGem-study). PLoS One. 2016;11. https://doi.org/10.1371/journ al.pone.0156304.

75. McConnell KJ, Delate T, Newlon CL. Impact of continuing professional development versus traditional continuing pharmacy education on learning behaviors. J Am Pharm Assoc. 2012;52:742-52. https://doi.org/ 10.1331/JAPhA.2012.11080.

76. Williams M, Peterson GM, Tenni PC, Bindoff IK. A clinical knowledge measurement tool to assess the ability of community pharmacists to detect drug-related problems. Int J Pharm Pract. 2012;20:238-48. https://doi.org/ 10.1111/j.2042-7174.2012.00188.x.

77. Zekan L, Mestrovic A, Seselja Perisin A, Portolan M, Jambrek N, Jager S, et al. Clinical knowledge of community pharmacists in Croatia for detecting drug-related problems. Int J Clin Pharm. 2017;39:1171-4. https://doi. org/10.1007/s1 1096-017-0546-.

78. Zekan L, Mestrovic A, Perisin AS, Bukic J, Leskur D, Rusic D, et al. Improving community pharmacists' clinical knowledge to detect and resolve drugrelated problems in Croatia: a before/after survey study investigating the efficacy of an educational intervention. BMJ Open. 2020;10:e034674. https://doi.org/10.1136/bmjopen-2019-034674.
79. Jorgenson D, Lamb D, MacKinnon NJ. Practice change challenges and priorities: a national survey of practising pharmacists. Can Pharm J (Ott) 2011;144:125-31.

80. Moczygemba LR, Barner JC, Roberson K. Texas pharmacists' opinions about and plans for provision of medication therapy management services. J Am Pharm Assoc. 2008;48:38.

81. Cook DA, Beckman TJ. Current concepts in validity and reliability for psychometric instruments: theory and application. Am J Med. 2006;119:166.

82. Schepel L, Lehtonen L, Airaksinen M, Ojala R, Ahonen J, LapattoReiniluoto O. Medication reconciliation and review for older emergency patients requires improvement in Finland. Int J Risk Saf Med. 2018;30:1931. https://doi.org/10.3233/jrs-180030.

83. Celikkayalar E, Puustinen J, Palmgren J, Airaksinen M. Collaborative medication reviews to identify inappropriate prescribing in pre-admission medications at emergency department short-term ward. Integr Pharm Res Pract. 2021;10:23-32. https://doi.org/10.2147/iprp.s280523.

84. Toivo T. Prospective medication risk management in primary care: enhancing coordination of care and community pharmacists' participation: Doctoral dissertation. University of Helsinki; 2020. http://urn.fi/URN: ISBN:978-951-51-6464-3

85. Auvinen K, Räisänen J, Voutilainen A, Jyrkkä J, Mäntyselkä P, Lönnroos E. Interprofessional medication assessment has effects on the quality of medication among home care patients: randomized controlled intervention study. J Am Med Dir Assoc. 2021;22:74-81. https://doi.org/10.1016/j. jamda.2020.07.007

86. Finnish Advisory Board on Research Integrity TENK. Responsible conduct of research and procedures for handling allegations of misconduct in Finland. 2012. https://www.tenk.fi/sites/tenk.fi/files/HTK_ohje_2012.pdf. Accessed 05 Aug 2018.

87. Finnish National Board on Research Integrity TENK. The ethical principles of research with human participants and ethical review in the human sciences in Finland. 2019. https://tenk.fi/sites/default/files/2021-01/Ethic al_review_in_human_sciences_2020.pdf. Accessed 05 Aug 2020.

\section{Publisher's Note}

Springer Nature remains neutral with regard to jurisdictional claims in published maps and institutional affiliations.
Ready to submit your research? Choose BMC and benefit from:

- fast, convenient online submission

- thorough peer review by experienced researchers in your field

- rapid publication on acceptance

- support for research data, including large and complex data types

- gold Open Access which fosters wider collaboration and increased citations

- maximum visibility for your research: over $100 \mathrm{M}$ website views per year

At BMC, research is always in progress.

Learn more biomedcentral.com/submissions 